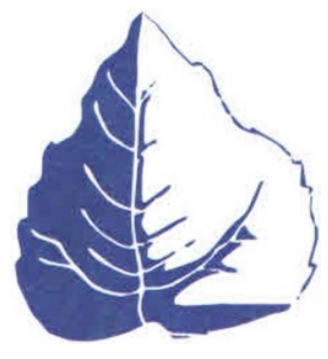

УДК 332.33

\section{ЭКОНОМИКА И УПРАВЛЕНИЕ НАРОДНЫМ ХОЗЯЙСТВОМ ECONOMY AND MANAGEMENT OF NATIONAL ECONOMY}

https://doi.org/10.23947/2413-1474-2020-4-4-26-32

Управление земельными ресурсами: инвентаризационный аспект

Ткачева О. А., Чернова А. И.

Новочеркасский инженерно-мелиоративный институт им. А. К. Кортунова, ДГАУ

(г. Новочеркасск, Российская Федерация)

Проанализированы основные недостатки системы управления земельными ресурсами, обоснована необходимость проведения комплекса работ по их инвентаризации. Изучена указанная процедура, определены ее задачи, описаны этапы проведения, рассмотрены основополагающие аспекты, произведены её SWOT-анализ, литературный анализ источников по изучаемой тематике. Показано состояние земельных ресурсов в хозяйствах Ростовской области.

Ключевые слова: земельные ресурсы, инвентаризация, управление, дистанционное зондирование Земли, геоинформационные технологии, SWOT-анализ.

Для цитирования: Ткачева, О. А. Управление земельными ресурсами: инвентаризационный аспект / О. А. Ткачева, А. И. Чернова // Экономика и экология территориальных образований. - 2020. - Т. 4, № 4. — C.26-32. https://doi.org/10.23947/2413-1474-2020-4-4-26-32

\title{
Land management: the inventory aspect
}

Tkacheva O. A., Chernova A. I.

Novocherkassk Engineering-meliorative Institute named after A. K. Kortunova, DGAU

(Novocherkassk, Russian Federation)

The article identifies the main shortcomings of the land management system, justifies the need for a set of works on land inventory. The given procedure is studied, its tasks are determined, the steps to its implementation are described, different fundamental aspects are performed and its SWOT-analysis is carried out. The state of land resources in the farms of the Rostov region is analyzed.

Keywords: land resources, inventory, management, remote sensing of the Earth, geoinformation technologies, SWOT analysis.

For citation: O. A. Tkacheva, A. I. Chernova. Land management: the inventory aspect. Economy and ecology of territorial formations, 2020, vol. 4, no 4, pp. 26-32. https://doi.org/10.23947/2413-1474-2020-4-4-26-32

Введение. Земля - основополагающий компонент национального богатства страны, выступающий пространственным базисом размещения народнохозяйственных объектов [1]. В социально-экономическом развитии общества земельным ресурсам принадлежит ведущая роль. Поэтому характер и масштабы использования земельных ресурсов следует рассматривать как один из решающих факторов, которые определяют темпы и эффективность развития национальной экономики, становления рыночных отношений. В связи с этим нерациональное использование земельных ресурсов является одним из негативных факторов, влияющих на экономику страны, поскольку затрагивает все стороны развития хозяйства. 
Для эффективного использования земельных ресурсов необходима налаженная система управления ими, содержащая актуальную, достоверную и точную информацию о земле и всех субъектах земельных отношений [2]. Целью данного исследования является изучение основных аспектов процедуры инвентаризации земель, установление её актуальности и выявление основных преимуществ и недостатков. В ходе исследования применялись системный подход, SWOT-анализ.

Теоретические аспекты инвентаризационных работ в системе управления земельными ресурсами. Обеспечение рационального использования земли в процессе производственной деятельности обуславливает актуальность изучения земельных ресурсов, их качественных и количественных характеристик, а также путей их современного и перспективного использования, т. е. необходимость эффективной системы управления земельными ресурсами. В настоящее время система управления земельными ресурсами имеет определенные недостатки, которые заключаются в отсутствии надлежащего учета и контроля за использованием земельных ресурсов, четкого определения границ земельных участков землепользователей и обновленной информации о качественном и количественном состоянии сельскохозяйственных земель [3]. Это свидетельствует о необходимости проведения инвентаризации земельных ресурсов, представляющей собой комплекс мероприятий по сбору информации о состоянии земель, их количественных и качественных характеристиках.

Основными задачами инвентаризации земель всех категорий являются определение собственника земли, состояния плодородия почв, развития негативных процессов, оценка использования земельных участков, выяснение причин ухудшения состояния земель, создание современного банка энергоинформационных данных о состоянии и использовании земель с обеспечением максимально широкого доступа к этой информации, разработка предложений по совершенствованию нормативноправовой базы.

Инвентаризационные работы входят в круг полномочий органов исполнительной власти, среди них урегулирование и рациональное использование земель, разграничение прав собственности на землю, формирование четких критериев для взимания налогов.

Основанием для проведения инвентаризации земель являются решения федеральных органов государственной власти, органов государственной власти субъектов Российской Федерации, органов местного самоуправления о проведении землеустройства, договоры о проведении землеустройства, заключаемые собственниками земельных участков, землевладельцами и землепользователями с землеустроительными организациями.

Финансирование работ по инвентаризации земельных ресурсов осуществляется из бюджетных средств, поступающих от сбора земельного налога и арендной платы за землю.

Проведение инвентаризации земель осуществляется в три этапа (рис. 1). Подготовительный этап включает в себя работы по сбору, анализу и изучению исходных материалов (топографические карты, данные землеустройства, градостроительная документация, материалы предыдущих инвентаризаций).

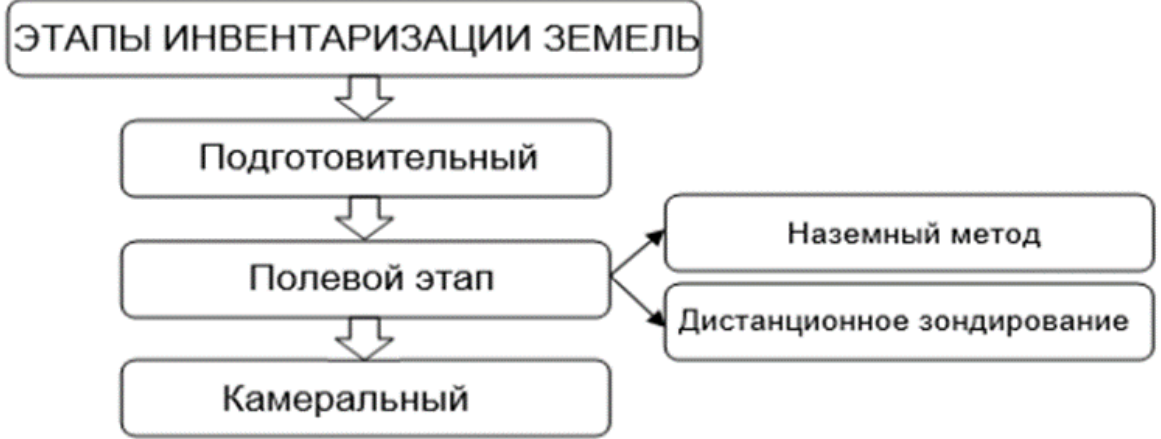

Рис. 1. Этапы инвентаризации земель 
Полевой этап включает в себя натурное обследование земельных участков и проверку правоустанавливающих и удостоверяющих документов. Особое место на данном этапе занимает использование метода дистанционного зондирования Земли (ДЗ3), позволяющего получать достоверную информацию о состоянии земельных ресурсов в кратчайшие сроки, без проведения дорогостоящих натурных обследований. Источниками данных ДЗЗ являются снимки, получаемые с помощью беспилотных летательных аппаратов и космических спутников (Ресурс П, Канопус, Worldview 3, Sentinel 2, Landsat8 и др.). В настоящее время широко используется методика аэрокосмических исследований в сочетании с геоинформационными технологиями и компьютерным моделированием.

Важно отметить, что наземные наблюдения целесообразно проводить в тех случаях, когда методами дистанционного зондирования данные о состоянии земель получить невозможно.

Камеральный этап - это составление инвентаризационной описи, перечня обследуемых земельных участков, формирование планов и карт территории, осуществление контроля и подготовки инвентаризационного дела [4]. Обработка и анализ данных инвентаризации ведется на основании геоинформационных технологий, которые работают на основе регулярно обновляющихся баз данных. Благодаря материалам дистанционного зондирования указанные базы пополняются оперативно и с наименьшими затратами средств (относительно полевых обследований).

На основании проведенных работ разрабатываются предложения по дальнейшему использованию данных, выявленных в ходе инвентаризации земель.

В настоящее время процедура инвентаризации земель активно совершенствуется. В табл. 1 представлен анализ литературных источников по исследуемой теме. Авторы изучают процедуру инвентаризации, выявляют ее недостатки.

Таблица 1

Анализ литературных источников

\begin{tabular}{|c|c|c|}
\hline Автор & Предмет исследования & Результат \\
\hline 1 & 2 & 3 \\
\hline $\begin{array}{l}\text { Т. Н. Жигулина, } \\
\text { В.А.Мерецкий [5] }\end{array}$ & $\begin{array}{c}\text { Недостатки процедуры } \\
\text { инвентаризации }\end{array}$ & $\begin{array}{c}\text { Авторы отмечают, что инвентаризация земель } \\
\text { проводится не во всех регионах и не имеет обяза- } \\
\text { тельного характера }\end{array}$ \\
\hline $\begin{array}{c}\text { Ю. А. Юнчик, } \\
\text { К. В. Клименко [6] }\end{array}$ & $\begin{array}{c}\text { Нормативно-правовая } \\
\text { база в сфере регулиро- } \\
\text { вания вопросов инвента- } \\
\text { ризации земель }\end{array}$ & $\begin{array}{c}\text { Выявлено отсутствие обновленной и действую- } \\
\text { щей нормативной правовой базы в сфере регули- } \\
\text { рования вопросов инвентаризации земель }\end{array}$ \\
\hline С. А. Поляков [7] & $\begin{array}{c}\text { Фискальная функция } \\
\text { процедуры инвентариза- } \\
\text { ции }\end{array}$ & $\begin{array}{c}\text { Автор обосновал необходимость в проведении } \\
\text { инвентаризации земель как фактора, решающего } \\
\text { проблему в сфере налогообложения }\end{array}$ \\
\hline $\begin{array}{l}\text { А. В. Федоринов, } \\
\text { М. Я. Черноусов [8] }\end{array}$ & $\begin{array}{c}\text { Управленческая } \\
\text { функция } \\
\text { инвентаризации земель }\end{array}$ & $\begin{array}{c}\text { Отмечена трудоемкость и финансовая затрат- } \\
\text { ность процедуры инвентаризации. Ученые пред- } \\
\text { лагают привлекать студенческие землеустрои- } \\
\text { тельные отряды для осуществления изучаемой } \\
\text { процедуры }\end{array}$ \\
\hline А. А. Гужин [9] & $\begin{array}{c}\text { Управленческая } \\
\text { функция } \\
\text { инвентаризации земель }\end{array}$ & $\begin{array}{c}\text { Автор подробно рассматривает активное исполь- } \\
\text { зование инвентаризации земель, в том числе и } \\
\text { для привлечения инвесторов, оперативности и ка- } \\
\text { чества принятия управленческих решений по рас- } \\
\text { поряжению земельными участками и прочно свя- } \\
\text { занными с ними объектами недвижимости }\end{array}$ \\
\hline
\end{tabular}


В процессе изучения процедуры инвентаризации осуществлен еe SWOT- анализ (табл. 2).

Таблица 2

SWOT-анализ процедуры инвентаризации

\begin{tabular}{|c|c|}
\hline Сильные стороны & Слабые стороны \\
\hline $\begin{array}{l}\text { • Осуществление контроля за использоанием и охраной зе- } \\
\text { мель. } \\
\text { • При инвентаризации земель определяется их местоположе- } \\
\text { ние, площадь, качественное состояние, а также причины, по- } \\
\text { влиявшие на изменение состояния земель. }\end{array}$ & $\begin{array}{l}\text { - Отсутствие обновленной информа- } \\
\text { ции о качественном и количествен- } \\
\text { ном состоянии сельскохозяйствен- } \\
\text { ных земель вызывает необходи- } \\
\text { мость проведения комплекса работ } \\
\text { по инвентаризации. }\end{array}$ \\
\hline Возможности & \begin{tabular}{|l} 
Угрозы \\
\end{tabular} \\
\hline $\begin{array}{l}\text { - Восстановление мелиоративно-неустроенных, нарушен- } \\
\text { ных и деградированных земель. } \\
\text { - Передача неиспользуемых земель в состав земель запаса. } \\
\text { - Выявление неиспользуемых, нерационально используе- } \\
\text { мых или используемых не по назначению и не в соответ- } \\
\text { ствии с разрешенным использованием земельных участков. } \\
\text { • Выявление земель, подверженных влиянию деградацион- } \\
\text { ных процессов (подтопление, переувлажнение и заболачива- } \\
\text { ние, засоление, эрозия, захламление, опустынивание и др.). } \\
\text { - Выявление наличия площадей резервов земель, потенци- } \\
\text { ально пригодных для хозяйственного использования. }\end{array}$ & $\begin{array}{l}\text { - Нерациональное использование } \\
\text { земли. }\end{array}$ \\
\hline
\end{tabular}

Составленная матрица показывает, как важно избежать угроз и какими способами это возможно сделать. Опираясь на литературный и SWOT-анализ, можно утверждать, что для усиления сильных и слабых сторон необходимо внедрение в процесс инвентаризации земель современных цифровых технологий, позволяющих быстро и качественно получать достоверную информацию о состоянии земельных ресурсов, тем самым устранить недостаток - отсутствие обновленной информации об указанных ресурсах. По результатам проведенных анализов видно, что основополагающим фактором усиления как сильных, так и слабых сторон является совершенствование нормативно-правовой базы в области инвентаризации земельных ресурсов.

Особое значение качественная информация имеет в сельском хозяйстве. Инвентаризация земель в общем своем проявлении представляет собой учет земельных ресурсов и поэтому тесно переплетается с сельскохозяйственной переписью, послужившей источником сведений для анализа состояния земельных ресурсов Ростовской области по городским округам (табл. 3), выполненного в рамках изучения указанной процедуры [10].

Важно отметить, что земли сельскохозяйственного назначения относятся в основном к средствам производства и используются в АПК, также присутствуют и в городских округах, занимая 72,8 \% от их общей площади. На табл. 3 видно, что в каждом городском округе Ростовской области сельскохозяйственные угодья не используются на $100 \%$. Всего на территории городских округов площадь неиспользуемых земель сельскохозяйственного назначения составляет 3393,8 га, или $12,9 \%$ от общей территории сельхозугодий. В г. Новочеркасске выявлен наименьший показатель неиспользуемых сельхозугодий - 38,5 га. Наибольший показатель неиспользуемых сельхозугодий отмечен в г. Шахты 624,4 га. В связи с этим необходимо выполнить инвентаризацию неиспользуемых земель сельскохозяйственного назначения для следующих целей: проведение глубокого анализа, определение причин неиспользования указанных земель, выявление основных нарушений, проведение мероприятий по вводу в оборот указанных земель. 
Таблица 3

Наличие и использование земельных ресурсов в хозяйствах

Ростовской области (по городским округам), га (2016 г.)

\begin{tabular}{|c|c|c|c|}
\hline & $\begin{array}{c}\text { Общая } \\
\text { площадь } \\
\text { земли }\end{array}$ & $\begin{array}{c}\text { Из нее сельскохо- } \\
\text { зяйственные угодья }\end{array}$ & $\begin{array}{c}\text { Из общей площади сельскохо- } \\
\text { зяйственных угодий фактиче- } \\
\text { ски использовались }\end{array}$ \\
\hline Всего по городским округам: & 36242,5 & 26368,0 & 22974,2 \\
\hline Ростов-на-Дону & 4600,5 & 1699,9 & 1163,9 \\
\hline Азов & 1876,7 & 1547,3 & 1162,1 \\
\hline Батайск & 2096,2 & 1254,6 & 917,0 \\
\hline Волгодонск & 5361,3 & 3808,2 & 3544,4 \\
\hline Гуково & 869,2 & 493,0 & 380,5 \\
\hline Донецк & 2893,2 & 2671,5 & 1434,2 \\
\hline Зверево & 1634,5 & 1512,6 & 2348,7 \\
\hline Каменск & 3136,3 & 2637,0 & 3401,8 \\
\hline Новочеркасск & 3908,1 & 3440,3 & 4516,6 \\
\hline Новошахтинск & 5408,2 & 4662,1 & 630,0 \\
\hline Таганрог & 1315,3 & 702,3 & 1314,9 \\
\hline Шахты & 3143,0 & 1939,3 & \\
\hline
\end{tabular}

Заключение. Рациональное использование земельных ресурсов - актуальная проблема. Подход к ее решению должен носить комплексный характер. Процедура инвентаризации земель является основополагающим условием на пути к эффективному управлению земельными ресурсами, так как она способна обеспечить максимальную экономическую выгоду.

\section{Библиографический список}

1. Вегера, С. Г. Земля как элемент национального богатства / С. Г. Вегера [Электронный реcypc] / Cyberleninka. - Режим доступа: https://cyberleninka.ru/article/n/zemlya-kak-elementnatsionalnogo-bogatstva/viewer (дата обращения: 17.11.2020).

2. Татаренко, Т. С. Роль инвентаризации земель в управлении земельными ресурсами / Т. С. Татаренко // Young Science. — 2014. - Т. 1, № 2. - С. 59-62.

3. Гиенко, Д. Г. Система управления земельными ресурсами. Описание проблем и вариантов их решения. Обзорная статья / Д. Г. Гиенко [Электронный ресурс] / Cyberleninka. — Режим доступа: https://cyberleninka.ru/article/n/sistema-upravleniya-zemelnymi-resursami-opisanie-problem-i-variantov-ihresheniya-obzornaya-statya (дата обращения: 21.09.2020).

4. Басова, В. В. Инвентаризация земель / В. В. Басова, А. С. Ладошкина, А. С. Коротин [Электронный ресурс ] / Студенческий научный форум-2018. - Режим доступа: https://scienceforum.ru/2018/article/2018002149 (дата обращения: 23.09.2020).

5. Жигулина, Т. В. Методические аспекты проведения инвентаризации земель сельскохозяйственного назначения, используемых сельскохозяйственными организациями / Т. В. Жигулина, В. А. Марецкий // Вестник Алтайского государственного аграрного университета. — 2016. № 8(142). - С. 84-88.

6. Юнчик, Ю. А. Нормативно-правовое обеспечение инвентаризации земель / Ю. А. Юнчик, К. В. Клименко, Е. И. Сильченко // Современные проблемы и перспективы развития земельно-имущественных отношений : сборник статей по материалам II Всероссийской научно-практической конференции. - Краснодар, 2020. — С. 315-319.

7. Поляков, С. А. Инвентаризация земли как один из способов воздействия пополнения бюджета в виде земельного налога / С. А. Поляков [Электронный ресурс] / Cyberleninka. — Режим доступа: 
https://cyberleninka.ru/article/n/inventarizatsiya-zemli-kak-odin-iz-sposobov-vozdeystviya-popolneniyabyudzheta-v-vide-zemelnogo-naloga/viewer (дата обращения: 02.10.2020).

8. Федоринов, А. В. Инвентаризация земель сельскохозяйственного назначения, как инструмент освоения неиспользуемых земельных участков / А. В. Федоринов, М. Я. Черноусов // Наука и инновации - современные концепции : сборник научных статей по итогам работы Международного научного форума. - Москва, 2019. - Т. 3. - С. 60-65.

9. Гужин, А. А. Инвентаризация земель как инструмент управления земельными ресурсами / А. А. Гужин // Вестник Московского государственного областного гуманитарного института. Серия: история, философия, политология, право. — 2015. - Т. 2, № 2-2(215). — С. 10.

10. Итоги всероссийской сельскохозяйственной переписи 2016 года [Электронный ресурс] / Ростовстат. — Режим доступа: https://rostov.gks.ru/folder/30533 (дата обращения : 17.11.2020).

Поступила в редакцию 24.08 .2020

Запланирована в номер 01.10.2020

\section{Об авторах:}

Ткачева Ольга Александровна, доцент кафедры кадастра и мониторинга земель Новочеркасского инженерно-мелиоративного института им. А. К. Кортунова, ДГАУ (346428, РФ, г. Новочеркасск, ул. Пушкинская, 111), кандидат сельскохозяйственных наук, allesgut75@mail.ru

Чернова Анна Ильинична, студентка 4 курса землеустроительного факультета Новочеркасского инженерно-мелиоративного института им. А. К. Кортунова, ДГАУ (346428, РФ, г. Новочеркасск, ул. Пушкинская, 111), achernova1999@mail.ru

\section{References}

1. Vegera SG. Zemlya kak element nacional'nogo bogatstva [Land as an element of national wealth]. Cyberleninka. (In Russ.)

2. Tatarenko TS. Rol' inventarizacii zemel' $v$ upravlenii zemel'nymi resursami [The role of land inventory in land management]. Young Science, 2014, 1;2: 59-62. (In Russ.)

3. Gienko DG. Sistema upravleniya zemel'nymi resursami. Opisanie problem i variantov ih resheniya. Obzornaya stat'ya [Land management system. Description of problems and solutions. Review article]. Cyberleninka. (In Russ.)

4. Basova VV., Ladoshkina AS., Korotin AS. Inventarizaciya zemel' [Land inventory]. (In Russ.)

5. Zhigulina TV. Metodicheskie aspekty provedeniya inventarizacii zemel' sel'skohozyajstvennogo naznacheniya, ispol'zuemyh sel'-skohozyajstvennymi organizaciyami [Methodological aspects of conducting an inventory of agricultural land used by agricultural organizations]. Bulletin of Altai state agrarian University, 2016; 8 (142):84-88. (In Russ.)

6. Yunchik YA, Klimenko KV., Sil'chenko EI. Normativno-pravovoe obespechenie inventarizacii zemel' [Legal support for land inventory]. Modern problems and prospects of development of land and property relations: collection of articles based on the materials of the II All-Russian scientific and practical conference, Krasnodar, 2020: 315-319. (In Russ.)

7. Polyakov SA. Inventarizaciya zemli kak odin iz sposobov vozdejstviya popolneniya byudzheta v vide zemel'nogo naloga [Land inventory as one of the ways to influence budget replenishment in the form of land tax]. Cyberleninka. (In Russ.)

8. Fedorinov AV. Inventarizaciya zemel' sel'skohozyajstvennogo naznacheniya kak instrument osvoeniya neispol'zuemyh zemel'nyh uchastkov [Inventory of agricultural land as a tool for developing unused 
land plots]. Science and innovation-modern concepts: a collection of scientific articles based on the results of the International scientific forum, Moscow, 2019, 3:60-65. (In Russ.)

9. Guzhin AA. Inventarizaciya zemel' kak instrument upravleniya zemel'nymi resursami [Land inventory as a land management tool]. Bulletin of Moscow state regional humanitarian Institute. Series: history, philosophy, political science, law, 2015; 2;2-2(215):10. (In Russ.)

10. Itogi vserossijskoj sel'skohozyajstvennoj perepisi 2016 goda [Results of the 2016 All-Russian agricultural census]. Rostovstat. (In Russ.)

Received 24.08.2020

Scheduled in the issue 01.10 .2020

\section{Authors:}

Tkacheva Olga A., associate professor, the faculty of Cadaster and monitoring Department, Engineering-meliorative Institute named after A. K. Kortunova, DGAU (111, Pushkinskay str, Novocherkassk, RF, 346428) PhD in Agricultural Sciences, associate professor, allesgut75@mail.ru

Chernova Anna I., the 4th year student, the faculty of land management, Engineering-meliorative Institute named after A. K. Kortunova, DGAU (111, Pushkinskay str, Novocherkassk, RF, 346428, ), achernova1999@mail.ru 